\title{
Silver Nanoparticles in Cosmetics
}

\author{
Swati Gajbhiye*, Satish Sakharwade \\ Department of Cosmetic Technology, LAD \& SRP College for Women, Nagpur, India \\ Email:"gajbhiyelswati@gmail.com
}

Received 20 February 2016; accepted 25 March 2016; published 28 March 2016

Copyright @ 2016 by authors and Scientific Research Publishing Inc.

This work is licensed under the Creative Commons Attribution International License (CC BY).

http://creativecommons.org/licenses/by/4.0/

(c) (i) Open Access

\begin{abstract}
This review is presented as a common interest in silver nanoparticles, their origin, activity, and toxicity in cosmetic. The application of nanotechnology and nanomaterials can be found in many cosmetic products including moisturizer, hair care products, makeup and sunscreen. Nanomaterials are now being used in leading cosmetics products, most commonly as chemicals used to give the protection. A silver nanoparticle is the potent and broad spectrum antimicrobial agent. This review paper looks into use of nano silver and provides an overview of current activity in this area.
\end{abstract}

\section{Keywords}

\section{Nanosilver Nanoparticles, Cosmetic, Toxicity, Application in Cosmetics}

\section{Introduction}

Nanotechnology is the study of nanoparticles, and by definition, a nanoparticle is any material measuring less than 100 nanometers in at least one dimension. Nano sized materials have unique optical, thermal, electrical, and/or magnetic properties and have been used in cosmetics and paints [1]. The use of silver nano is about $12 \%$ of all nano particles used in cosmetics (Figure 1) [2].

Lots of brain storming is going on, on the application of nanomaterials in cosmetic products in various forums. Nano materials give improved sensory properties and stability to cosmetics. Nano zinc oxide, titanium dioxide not only gives better feel and spread-ability to the cosmetic formulation but also gives better sun protection. Similarly nano silver also has improved antimicrobial spectrum than its macro molecule [4].

However the toxicity or safety issue is of concern owing to nano size and subsequent penetration and, or permeation through the skin when nanosilver is incorporated in cosmetic products. There is no unanimous opinion amongst scientists about toxicity of these particles. There are conflicting claims and counter claims and lack of agreement between researchers on safety for dermal use. Because of their size, these nanoparticles can easily

${ }^{*}$ Corresponding author. 


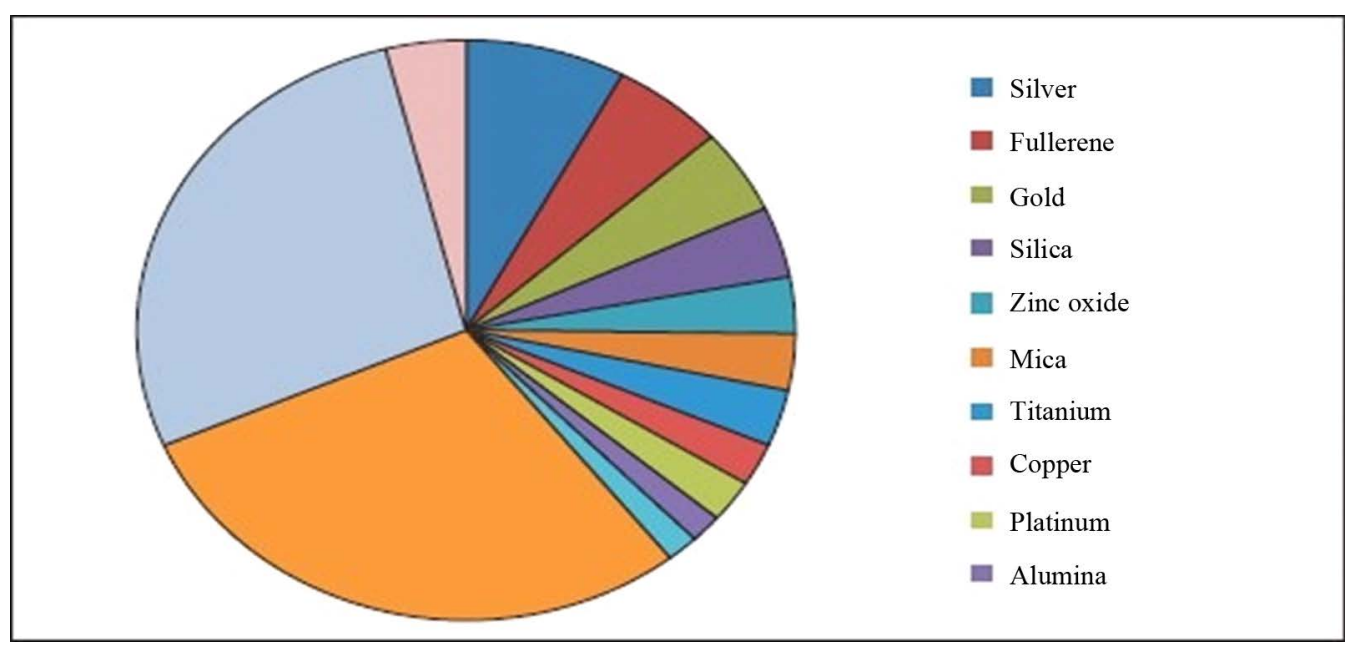

Figure 1. List of nano particles used in cosmetic products [3].

permeate in skin, then to the various organs. They may damage the cellular structures and DNA rendering the organ dead [4]. However a group of scientists at the University of California Santa Barbara claimed that, silver nanoparticles get flushed away, from blood stream, reducing toxicity considerably [5]. It is also reported that silver nanoparticles can protect some skin disease like atopic dermatitis [6]. The explanation of the protective effects is still not understood. It is suggested that silver can disrupt the bacterial cell wall. At minimal and reasonable concentration of silver, there are no side effects on human health [7]. Due to antibacterial properties of silver nanoparticles it can be used as preservatives in cosmetics, and in anti-acne preparation. For example, silver nanoparticles, which have antibacterial activity, are also being incorporated into toothpastes and shampoos as preservatives. Kim et al. observed that silver nanoparticles inhibit the growth of dermatophytes, making them potential anti-infective agent [8] [9]. Nano silver is also used in dietary supplement, because of its antibacterial, anti flu and cancer inhibitory effect. It also proves to be beneficiary in low blood count and bad skin [10]. With the emergence of nanoscience and technology, research has been initiated to exploit the unusual and unique properties of nanomaterials. Studies with various types of nanoparticles suggest that they may possess antibacterial and antifungal properties. Silver nanoparticles have been studied extensively in this regard. The literature suggests that, while the antimicrobial activity of silver nanoparticles may be due to the release of silver ions, it is also possible that they exhibit additional effect that cannot be explained solely by the release of silver ions in solution [11].

\section{Mechanism of Action of Silver Nanoparticles}

The silver nanoparticles get attached to the cell membrane and also penetrate inside the bacteria. The nanoparticles preferably attack the respiratory chain, cell division finally cell necrosis. The release of silver ions in the bacterial cells, enhance their bactericidal activity [12]. Silver nanoparticles show potential antimicrobial effects against infectious organisms, including Escherichia coli, Bacillus subtilis, Vibria cholera, Pseudomonas aeruginosa, Syphillis typhus, and S. aureus [13] [14]. Similarly studies were also done by J.S. Kim et al. to determine the relationship between free radical and antimicrobial activity and the result showed that free radical may be derived from the surface of silver nanoparticles and could be responsible for its antimicrobial properties [15].

These nanoparticles had significant antifungal activities against trichophyton mentagrophytes and Candida species (such as C. albicans, C. tropicolis, C. glabrata, C. parapsilosis, and C. krusei). Silver nanoparticles disrupt fungal envelope structure and lead to significant damage to fungal cells [16] [17]. Silver nanoparticles, kills bacteria by damaging the cell wall of bacteria [18] [19]. The antimicrobial efficacy of the nanoparticles depends on the size of the nanoparticles. Lower the particle size more efficacious they become [20]. Efficacy also changes with method of preparation of nanoparticles. For example AgNPs prepared with alginate having an average size of $7.6 \mathrm{~nm}$ exhibited the highest antibacterial activity among silver nanoparticles solution [21]. Silver also possesses healing properties. In case of silvernano particles the skin regenerating function of dermis cells is potentiated, resulting in faster wound recovery. This prevents the scar formation renders healed skin smooth [22]. 


\section{Surface Area of Nanoparticles}

As the size of the particle decreases, their surface area increases leading to an increase in their reactivity [23].

Antibacterial efficiency of Silver nanoparticles increases exponentially due their smaller size [24]. Okkyoung and Zhiqiang also given similar result in the study of surface area of nanoparticles for their antimicrobial properties stating that smaller particles size which has got the larger surface area to the volume ratios have greater antibacterial effect [25]. Similarly Nano silver has healing property and it repairs skin tissue [26]. Ag NPs has anti-inflammatory properties as well. Nadworny et al. confirmed that Ag NPs had anti-inflammatory effects and improved the healing process significantly [27].

\section{Nanoparticles-Penetrate through the Skin?}

The probable penetration of nano materials through skin when cosmetics are applied is of concern. Skin and hair care formulators exercise due care that the ingredients are delivered at proper sites. The skin is semi permeable in nature; therefore it will not allow even nanomaterials passage through it at ease. The study precisely concludes that nanoparticles in current cosmetic use do not penetrate through human skin, even in cases when the skin is damaged [28].

S. Kokura et al. also showed that Ag nanoparticles are not able to penetrate human skin. However, when the barrier function of human skin is disrupted, Ag nanoparticles on the skin surface may penetrate the skin. It may be possible that $0.2 \%$ to $2 \%$ of Ag nanoparticles could penetrate the skin (0.002 - $0.02 \mathrm{ppm}$ ). At these levels Ag nanoparticles did not show any toxicity [29]. Nanoparticles (20 to $200 \mathrm{~nm}$ ) contacting intact or partially damaged skin cannot penetrate skin barrier and permeate to lower strata making them safe as cosmeceuticals [30].

Nanoparticles with a diameter less than $10 \mathrm{~nm}$ could reach the deeper layer of the stratum corneum, while np larger than $40 \mathrm{~nm}$ could only reach 5 - $8 \mu \mathrm{m}$ into the stratum corneum [31]. Nanoparticles of chromium, silver, $\mathrm{TiO}_{2}$, and $\mathrm{ZnO}$ do not penetrate deeper than the stratum corneum [32].

\section{Silver Nanoparticles in Cosmetics}

Acute dermal toxicity studies on silver nanoparticle (SNP) gel formulation (S-gel) in Sprague-Dawley rats showed complete safety for topical application. These results clearly indicate that silver nanoparticles could provide a safer alternative to conventional antimicrobial agents in the form of a topical antimicrobial formulation [33]. Some special tooth creams for the neck of sensitive teeth contain nanoscale calcium phosphate (apatite) which produces a thin layer similar to natural tooth enamel, which is thus supposed to reduce sensitivity to pain. Tiny particles of nanometer-thin pigment can be found in make-up, nanoparticulate gold and silver is used in certain day and night creams to give the skin a fresher appearance [34]. GNS NanogistnanoverTM Premium make up range contains Nano silver, GNS NanogistnanoverTM Q10 Range contains Nano silver [2]. Nano silver is used in soaps, toothpastes, wet wipes, deodorants, lip products, as well as face and body foams [35].

\section{Skin Cleanser}

Nano silver containing cleanser soap was claimed to have bactericidal and fungicidal properties and was found useful in treating acne and sun damaged skin [36]. To prevent transmission of infectious diseases high efficacy within short exposure time, are important parameters. Nanosilver in concentration of 15 mg per liter in hand wash was found satisfying both parameters very effectively [19].

Researchers have discovered that silver nanoparticles can also be used to destroy yeasts such as Candida glabrata and Candida albicans, which cause infections in mouth can be killed by nanosilver and therefore can be incorporated in dentifrices [37].

Hence Silver nanoparticles have application in veterinary, pharmaceutical and biological products [38].

The nano silver skin gel, which contains 30 times less silver than silver sulfadiazine, is better choice for the skin of burn patients to treat infections [39].

\section{Silver Nanoparticles for Nanotoxicology Research}

It is well documented now that nanosilver has anti bacterial, fungicidal and wound healing properties [19] [37]. These effects are primarily due to a low level of silver ion release from the nanoparticle surface. Elaborate studies also proved that silver nanoparticles are more innocuous than the equivalent mass loading of silver salts [40]. 


\section{Toxicity}

Silver nanoparticles are not studied extensively for their probable toxicity, but particlesize does play an important role [41]. Dr. Emma Meredith, head of scientific and technical; services at the UK's cosmetic Toiletry and perfumery association (CTPA), says that if nano materials posed a risk or was unsafe as any other material it wouldn't be used in cosmetic. This is proved that nanomaterials don't penetrate to reach cutis [42]. It is necessary to consider various parameters like sizes, methods of preparation, variations in evaluation tests while building up evidence of possible Silvernano toxicity. The studies carried on different organisms and on cell culture did not reportedly produce any conclusive evaluation of silver nanoparticle toxicity [43] [44].

However this is imperative to study the intracellular activity and function of nanomaterials, for the development of effective and safe nanoparticle to be used as cosmeceuticals.

\section{Conclusion}

With the data collected from this study, we conclude that the silver nanoparticles are safe to use in cosmetics depending upon the particle size, as it seems that the smaller particles present higher toxicity compared with bigger nanoparticles. Further studies are needed to understand the exact role of free radicals in the antimicrobial activity of nanoparticles and the mechanisms of antimicrobial properties in the particles. Very few formulations containing nanosilver are available at this point of time, [2] because the complete potential of nanosilver is not explored. The nanosilver can be used for anti acne, anti dandruff, healing agent, anti scaring agent etc. in cosmetic formulation. Therefore further studies in this aspect will certainly be important and useful. However, further studies are also needed to examine cytotoxicity of nanoparticles towards human cells before using them in the cosmetics products and thus, more studies are needed to better understand the toxicity and safe use of silver nanoparticles in cosmetics.

\section{References}

[1] Greßler, S. and Gazso, A. (2010) Nanotechnology in Cosmetics. Nano Dossiers. http://hw.oeaw.ac.at/0xc1aa500e_0x0024f6b3.pdf

[2] (2006) Friends of the Earth Report—Nanomaterials, Sunscreens and Cosmetics: Small Ingredients Big Risks. http://www.nano.foe.org.au

[3] http://www.ncbi.nlm.nih.gov/pmc/articles/PMC3425166/figure/F2/

[4] Raj, S. and Jose, S. (2012) Nanotechnology in Cosmetic: Opportunities and Challenges. Journal of Pharmacy and Bioallied Sciences, 4, 186-193.

http://www.medicaldaily.com/new-non-toxic-silver-nanoparticles-may-soon-target-cancer-tumors-287122 http://dx.doi.org/10.4103/0975-7406.99016

[5] Iyer, S. (2014) New Non-Toxic Silver Nano Particles May Soon Target Cancer Tumors. Article from Medical Daily Science/Tech.

[6] Shoseyov, O. and Levy, I. (2008) Nano BioTechnology, BioInspired Devices and Materials of the Future. 322.

[7] European Commission Public Health: Are Silver Nanoparticles Safe? Implications for Health, the Environment and Microbial Resistance. http://copublications.greenfacts.org/en/silver-nanoparticles/index.htm

[8] Kim, K.-J. (2008) Antifungal Effect of Silver Nanoparticles on Dermatophytes. Journal of Microbiology and Biotechnology, 18, 1482-1484.

[9] Noorbakhsh, F. (2011) Antifungal Effects of Silver Nanoparticle Alone and with Combination of Antifungal Drug on Dermatophyte Pathogen Trichophyton Rubrum. International Conference on Bioscience, Biochemistry and Bioinformatics IPCBEE , 5, 364-367.

[10] (2014) Scientists Warn against Harmful Effects of Silver Nanoparticles Used in Cosmetics and More. http://cosmetics.specialchem.com/news/industry-news/scientists-warn-against-harmful-effects-of-silver-nanoparticlesused-in-cosmetics-and-more

[11] Mukherji, S., et al. (2012) Nano-Antimicrobials Progress and Prospects. In: Cioffi, N. and Rai, M., Eds., 226.

[12] Rai, M. (2009) Silver Nanoparicle as a New Generation of Antimicrobials. Biotechnology Advance, 237, 76-89. http://dx.doi.org/10.1016/j.biotechadv.2008.09.002

[13] Cho, K.-H., Park, J.-E., Osaka, T. and Park, S.G. (2005) The Study of Antimicrobial Activity and Preservative Effects of Nanosilver Ingredient. Electrochimica Acta, 51, 956-960. http://dx.doi.org/10.1016/j.electacta.2005.04.071 
[14] Morones, J.R., Elechiguerra, L.J., Camacho, A., Holt, K., Kouri, B.J., Ramirez, T.J. and Yocaman, J.M. (2005) The Bactericidal Effect of Silver Nanoparticles. Nanotechnology, 16, 2346-2353. http://dx.doi.org/10.1088/0957-4484/16/10/059

[15] Kim, J.S., et al. (2007) Antimicrobial Effect of Silver Nanoparticles. Journal of Nanomedicine: Nanotechnology, Biology, and Medicine, 3, 95-101. http://dx.doi.org/10.1016/j.nano.2006.12.001

[16] Kim, K.J., Sung, W.S., Moon, S.K., Choi, J.S., Kim, J.G. and Lee, D.G. (2008) Antifungal Effect of Silver Nanoparticles on Dermatophytes. Journal of Microbiology and Biotechnology, 18, 1482-1484.

[17] Mehnert, W. and Mader, K. (2001) Solid Lipid Nanoparticles Production, Characterization and Applications. Advanced Drug Delivery Reviews, 47, 165-196. http://dx.doi.org/10.1016/S0169-409X(01)00105-3

[18] Sondi, I. and Salopek-Sondi, B. (2004) Silver Nanoparticles as Antimicrobial Agent: A Case Study on E. coli as a Model for Gram-Negative Bacteria. Journal of Colloid and Interface Science, 275, 177-182. http://dx.doi.org/10.1016/j.jcis.2004.02.012

[19] Prabhu, S. and Poulose, E.K. (2012) Silver Nanoparticles: Mechanism of Antimicrobial Action, Synthesis, Medical Applications, and Toxicity Effects. Prabhu and Poulose International Nano Letters, 2, 32.

http://www.inl-journal.com/content/2/1/32 http://dx.doi.org/10.1186/2228-5326-2-32

[20] Agnihotri, S. (2014) Size-Controlled Silver Nanoparticles Synthesized over the Range 5 - $100 \mathrm{~nm}$ Using the Same Protocol and Their Antibacterial Efficacy. Journal of The Royal Society of Chemistry, 4, 3974-3983. http://pubs.rsc.org/en/content/articlehtml/2014/ra/c3ra44507k http://dx.doi.org/10.1039/c3ra44507k

[21] Van Phu, D., Quoc, L.A., Duy, N.N., Lan, N.T.K., Du, B.D., Luan, L.Q. and Hien, N.Q. (2014) Study on Antibacterial Activity of Silver Nanoparticles Synthesized by Gamma Irradiation Method Using Different Stabilizers. Nanoscale Research Letter, 9, 162. http://dx.doi.org/10.1186/1556-276X-9-162

[22] http://www.corsilver.com.hk/cor-technology.php?lang=1

[23] Pritchard, D.K. (2004) Literature Review_Explosion Hazards Associated with Nanopowders. Health and Safety Laboratory. http://www.hse.gov.uk/research/hsl_pdf/2004/hsl04-12.pdf

[24] AZoNano (2006) Silver Nanoparticles-How They Are Providing Environmentally Friendly Antibacterial Properties in Consumer Goods. http://www.azonano.com/article.aspx?ArticleID=1695

[25] Choi, O. and Hu, Z. (2008) Size Dependent and Reactive Oxygen Species Related Nanosilver Toxicity to Nitrifying Bacteria. Environmental Science \& Technology, 42, 4583-4588. http://dx.doi.org/10.1021/es703238h

[26] Woodruff, J. (2014) Small but Might. Soap, Perfumery and Cosmetic, 87, 163.

[27] Wong, K.K.Y. (2012) Silver Nanoparticles in Medicine: Is the Panacea Here? Nanomedicine: Nanotechnology, Biology, and Medicine, 8, 935-940. http://www.nanomedjournal.com/content/silvernanoparticlesinmed

[28] The 2011 Nanodermatology Society Position Statement on Sunscreens. https://ethics.iit.edu/NanoEthicsBank/node/2593

[29] Kokura, S., Handa, O., Takagi, T., Ishikawa, T., Naito, Y. and Yoshikawa, T. (2010) Silver Nanoparticles as a Safe Preservative for Use in Cosmetic. Nanomedicin: Nanotechnology, Biology, \& Medicine, 6, 570-574. http://dx.doi.org/10.1016/j.nano.2009.12.002

[30] Campbell, C.S.J., Contreras-Rojas, L.R., Delgado-Charro, M.B. and Guy, R.H. (2012) Objective Assessment of Nanoparticle Disposition in Mammalian Skin after Topical Exposure. Journal of Controlled Release, 162, 201-207. http://dx.doi.org/10.1016/j.jconrel.2012.06.024

[31] Zhang, M. (2013) Au Natural Nanoparticles Sun Protection. Cosmetic and Toiletries, 128, 440.

[32] Wiechers, J.W. and Musee, N. (2010) Engineered Inorganic Naoparticles and Cosmetics: Facts, Issues, Knowledge Gaps and Challenge. Journal of Biomedical Nanotechnology, 6, 408-431. http://dx.doi.org/10.1166/jbn.2010.1143

[33] Jain, J., Arora, S., Rajwade, J.M., Omray, P., Khandelwal, S. and Paknikar, K.M. (2009) Silver Nanoparticles in Therapeutics: Development of an Antimicrobial Gel Formulation for Topical Use. Molecular Pharmaceutics, 6, 1388-1401. http://dx.doi.org/10.1021/mp900056g

[34] Gleiche, M., Hoffschulz, H. and Lenhert, S. (2006) Nanoforum Report: Nanotechnology in Consumer Products. http://www.nanowerk.com/nanotechnology/reports/reportpdf/report64.pdf

[35] Nano in Cosmetics and Personal Care. http://www.nanoandme.org/nano-products/cosmetics-and-sunscreen

[36] Lohani, A., Verma, A., Joshi, H., Yadav, N. and Karki, N. (2014) Nanotechnology-Based Cosmeceuticals. ISRN Dermatology, 2014, Article ID: 843687. http://dx.doi.org/10.1155/2014/843687

[37] Chai, C. (2012) Silver Nanoparticles Help Cure Hard-to-Treat Mouth Infections. http://www.wiley.com 
[38] Bansod, S.D., Bawaskar, M.S., Gade, A.K. and Rai, M.K. (2015) Development of Shampoo, Soap and Ointment Formulated by Green Synthesised Silver Nanoparticles Functionalised with Antimicrobial Plants Oils in Veterinary Dermatology: Treatment and Prevention Strategies. IET Nanobiotechnology, 9, 165-171.

http://digital-library.theiet.org/content/journals/10.1049/iet-nbt.2014.0042 http://dx.doi.org/10.1049/iet-nbt.2014.0042

[39] Paknikar, K. (2009) New Nano-Silver Skin Gel May Help Improve Treatment of Burns. http://www.azonano.com/news.aspx?newsID=12729

[40] Krug, H., Wick, P., Nowack, B. and Müller, N. (2013) Human and Ecotoxicity of Synthetic Nanomaterials: Toxicity and Ecotoxity of Engineered Nano-Objects (ENO). Federal Office for the Environment FOEN, Bern, 17.

[41] Soutter, W. (2012) Silver Nanoparticles as Antimicrobial Agent. AZoNano News, 16 July 2012. http://www.azonano.com/article.aspx?ArticleID=3056

[42] Deschamps, M.J. (2012) Nano on Label. Soap, Perfumery and Cosmetic, 85, 57-58.

[43] de Lima, R., Seabra, A.B. and Durán, N. (2012) Silver Nanoparticles: A Brief Review of Cytotoxicity and Genotoxicity of Chemically and Biogenically Synthesized Nanoparticles. Journal of Applied Toxicology, 32, 867-879. http://dx.doi.org/10.1002/jat.2780

[44] Maass, G.J. (2008) Colloidal Science Laboratories, Silver Nanoparticles: No Threat to the Environment. https://www.purestcolloids.com/SilverNoThreat.pdf 